Revista Iberoamericana, Vol. LXXVIII, Núms. 238-239, Enero-Junio 2012, 193-208

\title{
LABERINTO (AS TIME GOES BY), DE GABRIEL TRUJILLO MUÑOZ: NOVELA DE LA HIBRIDEZ
}

\author{
POR \\ DALE KNICKERBocker \\ East Carolina University
}

Novelista, ensayista, poeta y crítico, Gabriel Trujillo Muñoz (Mexicali, 1958) es reconocido como una de las voces más prolíficas y originales de la literatura mexicana contemporánea. ${ }^{1}$ No deja de sorprender, pues, que a pesar de ganar el Premio Estatal de Literatura de su país en 1994, su novela corta Laberinto (as time goes by) (desde ahora en adelante Laberinto) haya recibido escasa atención. ${ }^{2}$ Es posible que este dato se deba a la extrema dificultad de lectura de esta obra, cuya estructura es tan laberíntica y cuyo contenido es tan polifónico y alusivo que retan los esfuerzos semióticos del lector.

Igualmente significativo es el hecho de que Trujillo, autor también de novelas negras y fantásticas, eligiese la ciencia ficción (CF) como vehículo genérico en este caso. Según Darko Suvin, la CF se caracteriza por "the presence and interaction of estrangement and cognition, and whose main formal device is an imaginative framework alternative to the author’s empirical environment” (7-8). Es decir, la CF presenta como hipótesis cognitiva elementos tomados por fácticos dentro de la narrativa, pero que no lo son en el mundo del autor, y que por lo tanto provocan un efecto de extrañamiento en el lector.

1 Véanse los estudios de Gonzalo Martré y Miguel Ángel Fernández. Trujillo es autor de más de cincuenta títulos como novelista, cuentista, poeta, ensayista, investigador y periodista. Ha recibido numerosos premios; entre ellos se destacan el Premio Estatal de Literatura en Ensayo (1990), Poesía (1994, 1996, 2002), Periodismo cultural (1992), Novela (1994) y Cuento (2000). Otros galardones incluyen el Premio Nacional de Ensayo Abigael Bohórquez en 1998 y el Nacional de Narrativa Colima (1999). También obtuvo el Binacional de Poesía Pellicer-Frost en 1996; el Excelencia Frontera (1998); el Charrobot concedido por la Asociación Mexicana de Ciencia Ficción y Fantasía en 1997 por su trabajo en pro de la CF mexicana; el Nacional de Poesía Bartolomé Delgado de León (2004); el Internacional de Narrativa Ignacio Manuel Altamira (2005); y el regional de novela Vandalay (2005).

De la misma forma, su obra novelística es de índole variadísima: incorpora novelas negras (Mezquite Road [1995], Mexicali City Blues [2009], y Tijuana City Blues [2009]), de ciencia ficción (Espantapájaros [1999], Laberinto [1995]), y de fantasía (Transfiguraciones [2008], Highclowd [2006]). Por supuesto, es una lista muy incompleta que no incluye sus obras como poeta, ensayista, periodista, etc.

2 El único análisis publicado hasta este momento es el de Anaïs Fabriol, quien ve el Laberinto como metáfora de la frontera entre México y EE.UU. 
Laberinto se ajusta perfectamente a esta definición: la trama se desarrolla a raíz de dos eventos del año 2078, ocasionados por fenómenos tecnocientíficos especulativos: el primero es la derridación, efecto apocalíptico desatado por Hans Boder y su grupo neo-nazi con fines genocidas que da comienzo a una época llamada la "Edad del Caos". La derridación provoca una psicosis en el noventa porciento de la humanidad: borra la frontera psicológica entre el yo y el no-yo, y hace que se pierdan el raciocinio y la capacidad de distinguir entre lo real y lo irreal. ${ }^{3}$ El otro suceso es la creación por los nazis del Laberinto al que hace referencia el título como refugio para huir de unos científicos anti-racistas, el Comando Guevara, que los persiguen. El Laberinto es un espacio-tiempo informado por el subconsciente colectivo humano donde coexisten simultáneamente todos los espacios y tiempos posibles, habidos y por haber, imaginarios y reales. Estos dos acontecimientos, la derridación y la creación del Laberinto, forman las metáforas centrales de la obra.

La derridación y el Laberinto constituyen también ejemplos de lo que Joseph Tabbi ha llamado "the technological sublime" (1), o lo sublime tecnológico. En términos generales, una obra estética sublime intenta paradójicamente representar un concepto que va más allá de nuestra capacidad de representación; un concepto imposible de definir mediante palabras, de explicar por medio de sistemas cognitivos existentes. ${ }^{4}$ El pensador francés Jean François Lyotard, en su estudio The Postmodern Condition: A Report on Knowledge (de ahora en adelante $P M C$ ), propone una relación entre lo posmoderno y lo sublime: "[t]he postmodern would be that which, in the modern, puts forward the unpresentable in presentation itself" (81). La experiencia sublime puede describirse como sobrecogedora, tremenda, incomprensible, inefable, inimaginable, trascendente; el concepto ha sido asociado con el rapto, la grandeza, lo sagrado, y el éxtasis. Fue Edmund Burke quien señaló por primera vez la otra cara de la moneda: la índole indefinible de la experiencia sublime puede inspirar no sólo admiración y placer, sino también asombro e incluso terror. Tabbi ha afirmado que estas mismas reacciones se notan ante tecnologías tan impresionantes que resulta imposible comprenderlas en su totalidad. Lo sublime tecnológico consiste en "[a] simultaneous attraction to and repulsion from technology, a complex pleasure derived from the pain of representational insufficiency” (1). Dicha insuficiencia produce una "conceptual indeterminacy” (3).

3 Burness E. Moore y Bernard D. Fine definen la psicosis así: “[a] form of mental disorder characterized by marked ego and libidinal regression" que provoca un "change in the patient's relationship with persons and objects of his or her environment"; a veces incluye una "fantasy that the world is destroyed and everybody is unreal" (156-7).

4 Formulado por primera vez en el primer siglo de la era cristiana por Longino, el concepto de lo sublime ha atraído la atención de pensadores de todas las épocas. Generalmente, se consideran las contribuciones de Edmund Burke e Immanuel Kant las más importantes; para buenos análisis de la evolución del concepto, ver los libros de James Kirwan y Phillip Shaw.

\footnotetext{
(3) Revista Iberoamericana, Vol. LXXVIII, Núms. 238-239, Enero-Junio 2012, 193-208 ISSN 0034-9631 (Impreso) ISSN 2154-4794 (Electrónico)
} 
Tabbi sostiene que la representación narrativa de tecnología que causa este efecto "has paradoxically produced one of the most powerful modes of modern writing [...]-a technological sublime" (1).

La ausencia de significación determinada es también una característica de la narrativa posmoderna; no es casualidad que Laberinto manifieste las características principales de esta tendencia literaria también: se destacan la autorreflexividad, la apariencia de intertextos de numerosos géneros (populares y cultos), las alusiones a personas, lugares, y eventos históricos y su recontextualización. Estos elementos sirven, en las palabras de Linda Hutcheon, para crear una literatura "self-conscious, self-contradictory, selfundermining" (1); para plantear una "transgression of the boundaries between genres, between disciplines or discourses, between high and mass culture" (18); y para "denaturalize" (2) o "de-doxify" (18) conceptos y creencias tomados por naturales o autoevidentes. Por lo tanto, los textos posmodernos -como lo sublime-son indeterminados; no dejan lugar a ninguna lectura definitiva porque, como afirma Mary Ellen Bieder, "the tension produced by the interweaving of incompatible genre intertexts creates a confusion of genre boundaries that thwarts closure and precludes a stable resolution"(60).

Así es Laberinto: el hilo de la historia (la persecución de los neo-nazis) se ve frecuentemente interrumpido por abundantes fragmentos interpolados sacados de una multitud de fuentes que llaman la atención a la índole ficticia del argumento. Dichos fragmentos comentan e interpretan los eventos históricos desde una abrumadora variedad de perspectivas diferentes e incluso contradictorias. Se encuentran juntos definiciones de diccionario, artículos enciclopédicos, estudios psicoanalíticos, reflexiones religiosas, entradas de diarios, cantares de gesta y hasta poemas escritos por víctimas de la derridación: así se transgreden las fronteras mencionadas anteriormente. No se presenta ninguna interpretación como privilegiada o correcta; al contrario, se sugiere una realidad múltiple y polimórfica, sin jerarquización. Es una obra formalmente híbrida y semióticamente indeterminada.

El presente ensayo pretende demostrar que Trujillo maneja magistralmente convenciones de la CF, elementos posmodernos y lo sublime tecnológico a fin de retratar el siglo xx como una pugna entre dos cosmovisiones, la moderna (representada por el nazismo) y la posmoderna. Se verá que esta hibridez, esta combinación de ingredientes, elabora un sabroso elogio a la diversidad humana, al mestizaje -asimismo representado como una especie de hibridez- ${ }^{5}$

La estructura novelística híbrida descrita anteriormente refleja la forma bizantina del Laberinto mismo, y por lo tanto el argumento requiere un resumen más extenso de lo normal, por el cual se piden disculpas al lector. Aunque las seis partes (tituladas

5 En este ensayo, usaré “mestizaje” para designar la mezcla de etnias e "hibridez” para referirme a cualquier otra combinación.

$\begin{array}{lllll}\text { ISSN 0034-9631 (Impreso) } & \text { ISSN 2154-4794 (Electrónico) }\end{array}$ 
“Casablanca”, “Laberinto”, “Caos”, “Despertares”, “Colapso” y “Retorno”) no relatan los eventos en orden cronológico, para facilitar la lectura y la comprensión del ensayo se va a imponer tal orden. Entre los científicos que trabajaban en el proyecto que hizo posible la derridación y el Laberinto se encontraban no sólo Boder y sus sicarios, sino también los miembros del Comando Guevara ya mencionados, liderado por Josel Almeida. Después del desastre, Anastasia Dax, líder de otro grupo anti-racista llamado la Hermandad del Espectro, que había robado varias naves prototipo, se puso en contacto con unas naves que exploraban el espacio profundo para que volvieran a ayudar en la reconstrucción de la humanidad, empresa en la cual ella desempeñaría un papel principal.

El gobierno terrestre envía la nave espacial Iliria a estudiar el fenómeno durante la época de reconstrucción posapocalíptica. Unas décadas más tarde, el Laberinto comienza a desintegrarse y uno de los tripulantes, el "holohistoriador" Francisco Sing, viaja sin permiso al interior del fenómeno para investigar. Al pasar adentro pierde la memoria y se convierte físicamente en el Minotauro mítico. La capitana Irene Dax (nieta de Anastasia) va tras Sing, experimenta la amnesia, se transforma en Ingrid Bergman, y entra en lo que el lector reconoce como el bar de la película Casablanca, donde se encuentra con los miembros del Comando Guevara, también amnésicos, convertidos en otros personajes de la película. La tripulación pierde contacto con Dax y Sing. Mediante algunos textos interpolados se revela que los nazis no pueden escapar porque no saben controlar el Laberinto, mientras que los científicos-comandos sí sabían manejar los resortes del fenómeno, pero han perdido esos conocimientos por la amnesia. Boder y sus hombres descubren la presencia de la capitana y los habitantes del bar y los persiguen por los vericuetos del fenómeno. Irene se separa de los otros y es capturada y torturada para revelar el secreto de cómo salir.

Mientras tanto, la tripulación, bajo el mando del oficial de comunicaciones Cristóbal Monk, consigue comunicarse con ella y manda un grupo armado para liberarla. Josel Almeida, también encerrada en el fenómeno, se despierta y recupera la memoria y, con ella, el control del Laberinto. Todos logran escapar y el Laberinto se colapsa. Dax, los otros oficiales de la Iliria y los comandos también recuperan la identidad, vuelven a la nave y, con la doctora Almeida deciden perseguir a Boder a través de la infinidad de universos por los que saben navegar para frustrar la correspondiente infinidad de atentados perpetrados o por perpetrar, aunque saben que en algunas realidades el malo sobrevivirá para triunfar. En el desenlace regresan a su propio universo en un momento anterior a la derridación para evitar que el evento tenga lugar.

Trujillo pone en primer plano la relación entre lo moderno y lo posmoderno desde el primer epígrafe, una cita del texto ya mencionado de Lyotard:

La tecnociencia actual realiza el proyecto moderno: el hombre se convierte en amo y señor de la naturaleza. Pero al mismo tiempo la desestabiliza profundamente, ya que bajo el nombre de 'la naturaleza' hay que contar también todos los constituyentes

\footnotetext{
(3) Revista Iberoamericana, Vol. LXXVIII, Núms. 238-239, Enero-Junio 2012, 193-208 ISSN 0034-9631 (Impreso) ISSN 2154-4794 (Electrónico)
} 
del sujeto humano [. . . ] El hombre quizá sea tan sólo un nudo muy sofisticado en la interacción general de las radiaciones que constituyen el universo. (n.p.)

Tratándose de términos tan discutidos y controvertidos como "modernidad", “modernismo", "posmodernidad” y "posmodernismo", es imprescindible definir el uso que se hará de ellos en este trabajo, puesto que no significan lo mismo en el contexto latinoamericano como en las culturas europeas y angloparlantes ${ }^{6}$. La modernidad se refiere a la época desde el comienzo del Renacimiento en Occidente en el siglo xv hasta el presente. La Weltanschauung moderna incluye el Humanismo y su cosmovisión antropocéntrica; la fe en la razón, el progreso y la emancipación aportada por la Ilustración en el siglo xviII; los avances científicos y la aplicación tecnológica de ellos que componen la tecnociencia de la cual habla Lyotard. En el $P M C$, el teórico francés afirma que, durante la primera parte del siglo xx, la pérdida de fe en los sistemas de pensamiento que pretendían abarcar y explicar toda la realidad, las gran recits (narrativas maestras o metanarrativas) como las religiones, el positivismo o la tecnociencia, dio lugar a una fuerte nostalgia que se manifiesta en las tendencias artísticas del Modernismo. Piénsese por ejemplo en la imagen del pescador quien, al final del poema modernista por excelencia, “The Waste Land” de T.S. Eliot, melancólicamente sigue "pescando" respuestas a las cuestiones existenciales, o quizá la salvación (90). ${ }^{7}$

Después de la Segunda Guerra Mundial surgió el posmodernismo tal y como Lyotard (y Trujillo) lo conciben, con su rechazo de las narrativas maestras como fuerzas opresivas y represivas. El fragmento arriba citado contrasta lo que Lyotard considera la esencia del pensamiento moderno, el proyecto, con una metáfora posmoderna del sujeto como nexo o nudo de radiaciones; cuestionan así las oposiciones binarias natural/humano y natural/cultural. Como señala Linda Hutcheon, lo posmoderno interroga y pone en duda nociones de lo que es la "humanidad", la "raza”, el "hombre” y la "mujer”, la "etnia” o la "sexualidad"; las entiende no como categorías "naturales", sino como construcciones culturales comunicadas mediante "what was once assumed to be the seamless, unified narrative representations of subjectivity” (23).

6 Existe un largo y fascinante debate sobre si se puede o no hablar de una posmodernidad o un posmodernismo en Latinoamérica donde el proyecto moderno se está experimentando de una forma geográfica, política, y económicamente desigual. Véanse los estudios fundamentales de John Beverley y Martin Hopenhayn, y los igualmente imprescindibles artículos de Neil Larsen y George Yúdice. Para mayor confusión, en el contexto latinoamericano el Modernismo fue un movimiento estético de finales del siglo xix que incluía características del Simbolismo, el Impresionismo, y el Surrealismo. La literatura más parecida a la posmodernista europea-estadounidense se llamaría vanguardista. No obstante, el uso de "posmoderno/ista/ismo" en ese sentido se ha extendido mucho en la América Latina. En el caso de Laberinto, la cuestión es irrelevante ya que, como indica el epígrafe citado, Trujillo Muñoz claramente hace uso de los conceptos en el sentido lyotardiano.

7 Para un buen resumen reciente de las muchas y variadas interpretaciones del poema, véase el estudio de Lawrence S. Rainey.

ISSN 0034-9631 (Impreso) 
De la nostalgia modernista nacieron bastantes movimientos, herederos del legado del Humanismo, de la Ilustración y de la tecnociencia, que intentaron imponer una ideología y una identidad cultural únicas, sacrificar lo particular por lo colectivo, reprimir cualquier atisbo de diferencia, y exterminar a los seres que no pertenecieran al grupo dominante, todo ello "in the name of 'spirit,' 'logic,' the progress of history and of 'reason'” (Battersby 40). El ejemplo paradigmático que Lyotard ofrece es el nazismo, cuya máxima expresión estética quizá fuera la manifestación de Nuremberg inmortalizada por Leni Riefenstahl (1902-2003) en su película "Triumph des Willens" (1935). Lyotard se refiere específicamente al nazismo como ejemplo de lo sublime: "[i]n the terror of Nazism [...] the spectator is struck with astonishment, is rendered 'dumb, immobilized, as good as dead'”("Sublime” 204). Según Lyotard, laposmodernidad no suplanta la modernidad, es una tendencia dentro de la modernidad que coexiste con ella. Lo posmoderno rechaza las gran recits que pretenden legitimar lo universal, pero sin nostalgia: como afirma Battersby, "[f]or Lyotard, it is the longed-for universality of reason that is linked to the 'terror' of modernity — and it is this absolute universality that the postmodern sublime disturbs and disrupts” (19). En la novela de Trujillo, lo sublime posmoderno subvierte la universalidad a favor de la hibridez, la diversidad.

En Laberinto, un fragmento de un libro titulado Protocolos secretos (escrito ca. 2250 por Gideous Ar), confirma el significado del nazismo en la obra, y por lo tanto merece ser citado largamente:

El siglo xx es un reservorio mitológico inexplotado. Consideren solamente la cantidad de héroes, traidores, iconos populares y estandartes de batalla que pasearon, de un lado a otro, durante el transcurso de esa centuria prodigiosa. Y a eso añádanle mártires, mesías y profetas de todas las cataduras y estilos. ¡Qué hermoso caldo de cultivo fue esa etapa de la humanidad! ¿Y qué decir de sus afanes de trascendencia, de sus espectáculos públicos, de sus hazañas monumentales? Auschwitz o Treblinka. ¿Lo recuerdan? O la plaza de Tiananmen. O el muro de Berlín. Y no olviden la sangre que corría por todas partes. Hubo guerras con armas nucleares y con lanzas de guerra. Todos los tiempos reunidos en un solo siglo. Todos los crímenes a la vuelta de la esquina.

¿Quién puede negar ahora que allí fue, entre nazis, revolucionarios, cabezas rapadas, surrealistas, punks y ecologistas, que todo dio comienzo? ¿Quién se atreve a decir que la derridación fue un accidente imprevisto? ¡Mentira! ¡Una pura y pinche mentira! La derridación fue el resultado de un proceso cultural que tuvo su inicio en el siglo xx. Sin los campos de concentración fascistas y sin los gulags del imperio soviético, nadie hubiera pensado en reconstruir al hombre, en volverlo un ser exclusivamente racional. O lo que es peor: voluntariamente irracional. (52)

Para Trujillo, como para Lyotard, el nazismo sirve como ideología moderna por excelencia; representa todas las metanarrativas modernas y las resultantes represiones truculentas.

\footnotetext{
Revista Iberoamericana, Vol. LXXVIII, Núms. 238-239, Enero-Junio 2012, 193-208 ISSN 0034-9631 (Impreso) ISSN 2154-4794 (Electrónico)
} 
Basta una pequeña muestra del discurso de Boder, sacada de un panfleto suyo de ca. 2068, para comprobar esta relación: "[l]as reglas de la naturaleza son precisas e inflexibles: sólo unos cuantos tienen el derecho de preservar sus genes para el futuro, de moldear el rostro del hombre que viene. La degeneración es una burla ante el rostro de Dios, una blasfemia” (74). Para Boder, ese "rostro" debe poseer los rasgos de una sola raza. El líder nazi invoca un "derecho" basado en la naturaleza. Pero, según el pensamiento posmoderno, "la naturaleza" y lo "natural” no son fenómenos existentes a priori, antes de ser pensados, sino conceptos, construcciones culturales: como dice Hutcheon, “[e]ven nature [...] doesn’t grow on trees” (2). Además, Boder impone como patrón una noción teleológica del tiempo y de la historia: ésta sólo puede ir en uno de dos sentidos, o en "auge” o en "ocaso”, o hay "progreso" o hay "degeneración”. La cosmovisión de Boder implica una suerte de "Edad de Oro" o "Edén” previa a una "caída”, -elementos comunes a un sinfín de mitologías. Esta perspectiva demuestra una nostalgia muy moderna- según Eliot, añoramos el invierno cada abril porque "winter kept us warm" (69). El nazismo manifestaba lo que Lyotard llama "the nostalgia for presence felt by the human subject" (PMC 79) o "the nostalgia of the whole and the one” (PMC 81); es decir, deseaba volver a un origen -mítico- cuando sólo hubiera una raza, por rechazar una "primavera" multiracial.

Como buena novela posmoderna, Laberinto es paradójica: plantea ideas para aparentemente socavarlas mediante la ironía y la parodia. Como observa Hutcheon, el posmodernismo es inevitablemente un "paradoxical postmodernism of complicity and critique, of reflexivity and historicity, that at once inscribes and subverts the conventions and ideologies of the dominant cultural and social forces of the twentieth-century western world" (11). Para criticar las consecuencias de la cosmovisión moderna es imprescindible invocarla, y la cosmovisión posmoderna tampoco se libera de un escrutinio crítico, puesto que toda ideología padece de paradojas.

Por ejemplo, la derridación, así bautizada en honor al pensador quizá más asociado con la posmodernidad, Jacques Derrida, constituye una metáfora típicamente posmoderna en que presenta una paradoja o aporia en términos derridianos. Según Derrida, los signos sólo se refieren a más signos ad infinitum, aplazando así cualquier significado fijo o referente trascendental que los anclase. ${ }^{8}$ Según sus detractores, este "juego libre de interpretación” resulta en un caos semántico, y Trujillo se vale del conocimiento del lector de este trasfondo intelectual para brindar una parodia de la deconstrucción y, por asociación, de la posmodernidad. ${ }^{9}$

Esta burla se manifiesta en numerosas descripciones de la derridación. Por ejemplo, la Enciclopedia Galáctica (ca. 2133; desde ahora EG) nota que el propósito de la

8 Ver Writing and Difference (1978).

9 Véase por ejemplo el ensayo de Wolin, a quien Derrida puso un juicio por afirmar que el pensamiento deconstruccionista podría servir para borrar la distinción entre el nazismo y el no-nazismo.

Revista Iberoamericana, Vol. LXXVIII, Núms. 238-239, Enero-Junio 2012, 193-208
ISSN 2154-4794 (Electrónico) 
derridación era atravesar las divisiones entre universos de la misma forma que Derrida deconstruía la relación entre significante y significado: “[p]retendía crear túneles en la madeja espacio-temporal donde se pudieran comunicar los universos múltiples que existen a la vez" (22). Así se establece un paralelo metafórico entre el supuesto "caos semántico” de la deconstrucción y la Edad del Caos provocada por la derridación.

El efecto psicológico que el evento produce también es una metáfora paródica del afán posmoderno de borrar fronteras. Según la $E G$, la derridación induce a la psicosis; es decir, disuelve los límites del ego, de la identidad: “[...] trastocó los puntos referenciales de nuestra psique al deslizar el espectro psicotrópico hacia las fronteras de los sueños colectivos. El ser humano se volvió el hombre de las mil máscaras” (Laberinto 22-23). Esta noción de identidad se parece a la de la posmodernidad expresada en el epígrafe de Lyotard, y es vinculada a la noción de la hibridez. La deconstrucción semiótica se vuelve deconstrucción del sujeto.

De la misma forma, la derridación derriba la división entre lo real y lo irreal, como observa Gervasio Munch en su libro Historias de terror para abuelitas (ca. 2137): “[e] n ese proceso, la realidad, desde la perspectiva de la humanidad, se volvió elusiva, engañosa, cambiante en cada parpadeo" (Laberinto 18). Aunque la idea presentada es de índole posmoderna, la alusión al pintor expresionista Eduardo Munch es obvia y ubica al artista claramente dentro de la tendencia modernista, ya que su obra más famosa, Skrik (El grito) es una expresión de terror existencial. El proceso enajenador descrito es paradójico: es a la vez posmoderno, porque se regocija en y celebra la incertidumbre, y moderno, porque alude a una reacción angustiada hacia el caos y añora la certidumbre de las metanarrativas.

En el mismo texto interpolado, Trujillo también alude al físico Werner Heisenberg, científico que afirmó que la observación de un fenómeno necesariamente lo cambia, un concepto frecuentemente citado por posmodernistas: "el universo se redescubrió como una entidad relativa, transitoria y fundamentada en la óptica peculiar de cada espectador" (18). Thelonius Azrael, en Los caminos del caos (ca. 2098), se hace eco del nihilismo de Freidrich Nietzsche y del concepto de dasein del fenomenólogo Martin Heidegger: "[l]a vida entera carece de significado. [...] La vida entera frente al espejo de la nada, frente al colapso del tiempo. El ser-ahí-en-el-mundo-que-se derrumba” (17).$^{10} \mathrm{La}$ EG dice de la Edad del Caos que "hubo varias catástrofes provocadas por la ilusión de que 'nada importaba', que 'todo era un juego'. A este tiempo también se le conoce como el tiempo del nihilismo activo” (57-8); otra referencia a Nietzsche, uno de los filósofos que más influyó en la cosmovisión posmoderna. Finalmente, cabe señalar que la enciclopedia anteriormente citada relaciona la derridación explícitamente no sólo con el siglo xx, sino más específicamente con la estética del período: "su gusto estético está ligado a

${ }^{10}$ No hay que olvidarse de que Heidegger fue partidario de los nazis durante algún tiempo.

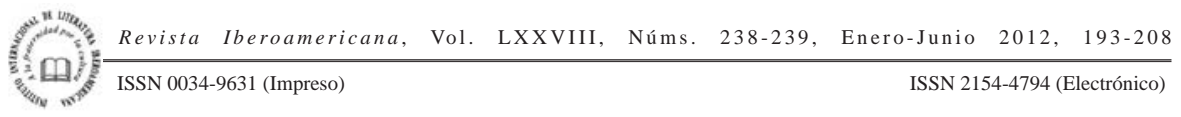


concepciones artístico-ideológicas pertenecientes al siglo veinte” (23). Este empleo de alusiones que a veces parecen paradójicas o contradictorias entre sí para así crear una variedad de posibles significados es una técnica propia de la narrativa posmoderna.

La representación de la derridación (y, mediante ella, de la posmodernidad) es, pues, típicamente posmoderna por paródica y paradójica: por un lado, la derridación que causa tanto sufrimiento está metafóricamente relacionada con la cosmovisión posmoderna y su afán de transgredir oposiciones binarias y categorías. Por otro, son los nazis/modernos quienes hacen uso de ella; además, como se verá más adelante, el mismo instrumento de destrucción crea una tabula rasa que hace posible una sociedad más libre e igualitaria. La derridación es a la vez herramienta de genocidio y fuerza liberadora, y un ejemplo perfecto del "posmodernismo paradójico de complicidad y crítica” al que se refería Hutcheon. Trujillo parece sugerir que ya no hay inocencia: vivir en estos tiempos que nos tocan significa convivir con las paradojas de la vida y hacer las paces con ellas.

La clave de la presente interpretación consiste en una última ironía que Trujillo nos brinda. Boder creía que solamente los hombres más evolucionados evitarían volverse irracionales y dejarse llevar por la emoción que más definía al protohombre, el miedo. Como dice su encargado de comunicaciones interestelares, el comandante Gor Kital, durante su interrogatorio por Anastasia Dax:

[...] lo que pretendía era un aceleramiento de la especie, una división tajante [...] para seleccionar a los humanos aptos de los no aptos. [... Su teoría era simple: un humano apto era aquel que estaba más alejado de sus ancestros primates y por lo tanto no vivía bajo la ley de los instintos, sino únicamente de la razón. La derridación funcionaría como una prueba de inteligencia [...] (78)

El líder racista daba por sentado que los menos afectados serían los “arios”; no obstante, esa arma tan devastadora tiene el efecto contrario al que Boder había previsto, como concluye Igor Astroski Muñoz en su estudio La derridación y sus paradojas (ca. 2321): “[m]etafóricamente hablando, podemos afirmar que aquellos que contaban con una mayor riqueza genética [...] tuvieron mejores posibilidades de salir indemnes, tuvieron anticuerpos más poderosos y eficaces para combatir el virus de la derridación" (Laberinto 81). Este dato hace resaltar la índole paradójica de la derridación: arma genocida y motor de un proceso de selección anti-natural impuesto por la tecnociencia, al final sirve para comprobar la verdadera lección de la selección natural darwiniana: la exogamia fortalece la especie.

Trujillo hunde su pluma en las raíces dieciochescas de la modernidad, en el despotismo ilustrado paternalista de la Ilustración, poniendo en evidencia que ningún individuo o colectividad tiene derecho a tomar decisiones por otras personas, -como hizo Boder. De nuevo, surge una paradoja: al actuar para prevenir la catástrofe, la tripulación de la Iliria

\footnotetext{
Revista Iberoamericana, Vol. LXXVIII, Núms. 238-239, Enero-Junio 2012, 193-208 ISSN 0034-9631 (Impreso) ISSN 2154-4794 (Electrónico)
} 
cambia el rumbo de la historia sin consultar con nadie; además, el nazi todavía no ha cometido ningún delito: “-Pero si evitamos la derridación -intervino Francisco Sing-, ¿qué va a ocurrir? Vamos a trastocar otra vez el universo, la historia de la humanidad. Y sin su permiso", a lo cual Almeida responde "[e]n este momento, Boder es tan inocente como usted o como yo. Él es sólo una posibilidad criminal a futuro” (137). Ante esta situación, la capitana decide que puede vivir con tal cargo de conciencia, y van por él.

Las variopintas definiciones del Laberinto también indican la naturaleza apórica de esta metáfora, ya que consisten principalmente en declaraciones paradójicas como la siguiente sacada del ensayo "La punkerización del cosmos” escrito por Katrina Qifer ca. 2178:

El Laberinto es una metáfora del mundo -o del universo, como se prefiera-: cambia según nuestros deseos, sí, pero también lo hace sin tomarlos en cuenta. Es la memoria colectiva de una humanidad amnésica, que poco a poco va recuperando sus recuerdos, que paulatinamente vuelve a tomar conciencia de sus mitos y de su historia, de sus sueños y pesadillas. Es la deconstrucción de la nada, el repoblar del universo. (19)

Oésta que profiere el pianista/científico/comando del bar: "[El Laberinto] [e]s como una composición sin autor que se toca a sí misma” (21). O la de esta conversación: “-Todo comienza donde tú digas- precisó el hombre del piano. [...] -Todo comienza cuando uno sueña- respondí con tardanza. [...] Por supuesto, ambos estábamos en lo correcto. Y, a la vez, equivocados” (13). Juan In-Zef, en su Crítica a la razón holotemporal (ca. 2465), obvia alusión a Kant, lo llama "no-espacio y no-tiempo" (66). Hasta el Diccionario Galáctico, que como autoridad que define lo real debería abstenerse de autocontradicciones, se refiere a él como "estructura sin estructuras" (38).

No obstante, a fin de cuentas y a pesar de las parodias y paradojas, Laberinto apoya apasionadamente un valor que se ve claramente relacionado con la posmodernidad: la diversidad humana que, irónicamente, el uso de la derridación aumenta. Este apoyo se manifiesta metafóricamente por medio de nombres alusivos y la consiguiente recontextualización de los elementos aludidos. Además, Laberinto es una novela híbrida no sólo formalmente, sino temáticamente también: la reiteración del motivo de la hibridez plantea y desarrolla el elogio de la diversidad racial y cultural, permeando la sustancia misma de la obra.

Sería imposible en un formato tan breve examinar todos los juegos onomásticos alusivos de los que tanto hace gala el autor. Pero están bien a la vista: no hay que buscar más allá de la hibridez lingüística del título, técnica que reaparece en la definición que el pianista de Rick's ofrece del Laberinto: "Nowhere. Este sitio es nowhere" (20, énfasis en el original). Son claramente metáforas del valor de la diversidad cultural.

La primera dedicatoria apoya esta hipótesis: “[p]ara Federico Schaffler, explorador de laberintos y quimeras” [n.p.]. La figura de la quimera se originó en la mitología

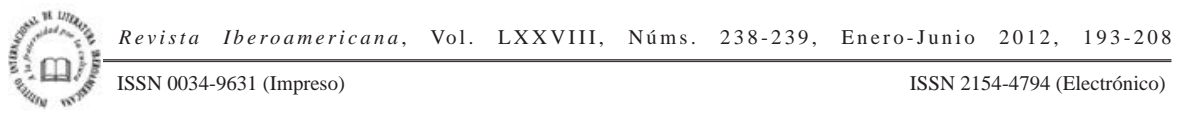


griega: hija del dios Tifón, era un monstruo de cabeza leonina, cuerpo de cabra, y cola de serpiente (Cirlot 46). Esta mezcla de especies sirve de metáfora de la celebración de mestizaje que Trujillo ofrece -y no nos olvidemos del Minotauro/Francisco Sing, uno de los héroes. De igual forma, sugieren un concepto posmoderno de la identidad humana como punto de encuentro o nexo de influencias, inestable y cambiante, que el autor cita en el epígrafe de Lyotard. Pero la expresión más explícita de esta idea la ofrece el "barman":

[1]o que pasa, si no lo sabías, es que nosotros somos un reservorio de imágenes donde lo realy lo imaginario se entrecruzan [...] Somos simples proyecciones multidimensionales en una frontera inestable entre los distintos tiempos y espacios que aquí coinciden. No somos ni seres de carne y hueso ni somos fantasmas. Más bien, una especie híbrida. (26)

Aunque el personaje está hablando solamente de los habitantes del Laberinto, mediantela ironía dramática el lector sabe que la descripción vale para casi todos los supervivientes de la catástrofe.

Los nombres mestizos de los personajes que sobreviven el evento apocalíptico subrayan esta hibridez: Francisco Sing, Cristóbal Monk, Thelonius Azrael... todos indican ascendencia de etnia mixta. Trujillo juega a una suerte de genética recombinante literaria, ya que casi todos los nombres multiculturales tienen un significado (sea simbólico o irónico) relacionado con el oficio o personalidad del personaje. Cristóbal Monk es una combinación obvia del también explorador Cristobal Colón y el músico de jazz Thelonius Monk. El personaje Monk es oficial de comunicaciones, de ahí la relación con la música; además, la estructura misma de la obra se parece a una pieza de jazz, forma musical conocida por la improvisación y la inclusión de fragmentos de distintas composiciones. Thelonius Azrael, autor de un estudio sobre el neo-nihilismo, es una mezcla de este mismo músico y el arcángel de la muerte de las tradiciones del islam y del cristianismo. El nombre "Gervasio Munch" mencionado arriba alude no sólo al pintor noruego, sino a uno de los grandes tesoros de la cultura mexicana: las ruinas mayas de San Gervasio en Cozumel. Además, los tripulantes que entran en el Laberinto cobran por lo menos una identidad más: uno de los residentes del bar explica que cuando salieron a explorar el fenómeno "[l]o más que encontramos fueron monstruos y quimeras [...] Como tú, mi querida Ingrid Bergman” (18). Ingrid Bergman es simultáneamente la actriz, el personaje Ilsa Lund de "Casablanca" y la capitana Irene Dax, perfecta metáfora del concepto posmoderno de la identidad. Tres fueron los científicos que crearon las teorías y la tecnologías necesarias para la derridación y la construcción del Laberinto: Theodore Atwitz, Takeo Misha y Alejandro Peña, y tres también sus distintos orígenes, demostrando lo fructífera que es la multipicidad cultural. La recombinación y la recontextualización onomásticas así subrayan simultáneamente la oposición entre las dos cosmovisiones y su relación con la diversidad étnica y cultural.

\footnotetext{
Revista Iberoamericana, Vol. LXXVIII, Núms. 238-239, Enero-Junio 2012, 193-208 
Además, se ve en los nombres un "mestizaje” de alusiones populares y cultas juntas, otro aspecto posmoderno.

Pero el juego no termina ahí: el apellido "Dax" compartido por la capitana y su abuela es una alusión metaficticia a un personaje de la serie de televisión "Star Trek: Deep Space 9”, Jadzia Dax. ${ }^{11}$ Ésta pertenecía a una raza que elegía a los individuos más dotados física, intelectual y emocionalmente para recibir symbiants, seres simbióticos de una raza alienígena, dentro de su cuerpo. La psique resultante era una combinación no sólo de las personalidades de los dos entes, sino además la suma de las experiencias de todos los anfitriones anteriores, y los symbiants vivían varios siglos. Las dos héroes Dax son, pues, ejemplos de lo que puede resultar de una mezcla de razas y culturas, a la vez que constituyen una metáfora del concepto posmoderno de la identidad y subrayan el conflicto entre esta cosmovisión y la del nazismo.

La cita a continuación, reflexiones de la heroica Josel Almeida en su diario, une los aspectos más sobresalientes aquí comentados:

¿Qué es la historia? ¿Qué es el mito? Dos relatos que difieren en minucias, dos versiones complimentarias de un mismo suceso. Ved el caso de la nave especial Iliria o del comando de sabotaje o de la propia derridación. ¿Son mitos o son historia? ¿A quién le interesa hacer semejantes distinciones? Mejor dejarlas vivir en sus propios términos, con sus eternas paradojas.

Por eso cuando alguien me pregunta qué fue de Hans Boder [... ] a mi vez le pregunto a quien me interroga de qué espacio temporal me habla o en qué universo ubica tal acontecimiento. [...] después de la derridación [...] ya ningún ser humano puede hablar de un sólo universo habitable. Uno ya no es solamente uno mismo, sino un conglomerado personal de fantasías y realidades. (139-40)

La historia es una narrativa maestra: aspira a establecer una correspondencia fija entre momento, hecho y una interpretación de ellos. Aspira a un estatus autoritativo y, por lo tanto, autoritario. Una explicación histórica pretende ser la única considerada válida. Es una idea moderna, reconfortante. Poner un discurso que se considera una explicación ficticia de datos (el sol atraviesa el cielo llevado por Apolo y su carro) en el mismo nivel de consideración que la historia es subvertir jerarquías que pasan por auto-evidentes, una práctica posmoderna. Se yuxtapone a la historia la noción de que coexisten en el mismo espacio y el mismo tiempo una multitud de universos o la "teoría del multiverso", que la realidad es "híbrida", y la proposición que el individuo tampoco es individual, sino un "conglomerado". ${ }^{12}$

${ }^{11}$ La serie duró siete temporadas (1993-1999), período que coincide con la escritura de la novela.

${ }_{12}$ La teoría del llamado multiverso fue propuesta originalmente por el físico David Deutsch en The Fabric of Reality (1997) y ha ido cobrando credibilidad en la comunidad científica. Además del libro citado de Deutsch, véase el estudio de Martin Rees.

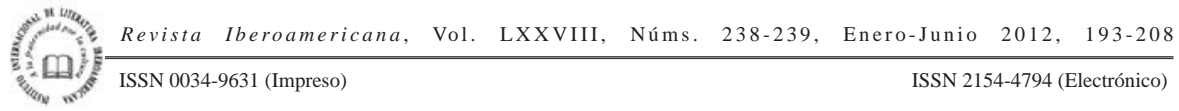


Laberinto ofrece una experiencia lectiva que presenta un conflicto entre la cosmovisión moderna y la posmoderna mediante el empleo de las convenciones de la CF, de las metáforas de lo sublime tecnológico, de la interpolación de textos divergentes y contradictorios, y de las paradojas. La nostalgia moderna nazi sobre una pureza racial inicial mítica en nombre de la ciencia y la razón se deconstruye mediante la violación lógica del principio científico darwiniano de que la exogamia fortalece la especie. Trujillo Muñoz se burla de su deconstrucción al mismo tiempo que afirma los valores asociados con este pensamiento: una "critique of humanism and positivism [...] questioning the validity of metanarratives of legitimation and emancipation, [...] of unity and universality", a favor de "smaller and multiple narratives which seek no universalizing stabilization or legitimation" (Battersby 24). Laberinto reconoce, acepta y celebra el mestizaje o la hibridez en todas sus formas y acoge en su seno la naturaleza parodójica o apóretica del pensamiento humano. La obra constituye, por encima de todo, un elogio a la diversidad humana, al mestizaje.

Merece la pena hacer una pequeña digresión para notar que Laberinto fue escrito al mismo tiempo que surgía el llamado movimiento "McOndo", el nombre constituye a la vez una alusión paródica al famoso pueblo Macondo de Cien años de soledad, de Gabriel García Márquez, novela paradigmática del realismo mágico, y al igualmente paradigmático ejemplo de la globalización económica, McDonald's. "McOndo" es un significantehíbrido cuyo significado es un concepto cultural mestizo. En la "Presentación" de la primera antología de cuentos del movimiento (McOndo 1996), que ha llegado a ser considerada el manifiesto del mismo, Alberto Fuguet y Sergio Gómez expresan el deseo de un gran número de autores relativamente jóvenes de escribir sobre su realidad, una realidad que describen así: "[n]uestro país McOndo es más grande, sobrepoblado y lleno de contaminación, con autopistas, metro, Tv-cable y barriadas. En McOndo hay McDonald's, computadores Mac y condominios, amén de hoteles cinco estrellas construidos con dinero lavado y centros comerciales gigantescos" (15). ${ }^{13}$

Por lo tanto, los escritores McOndo rechazaron la tradición del realismo mágico que había llegado a fetichizarse, a convertirse en estereotipo de la literatura latinoamericana porque, como afirmó Eduardo Paz Soldán, otro progenitor del movimiento, “[l]as

${ }^{13}$ Cuenta Fuguet que, cuando participaba en el prestigioso International Writers Workshop en la University of Iowa, en pleno Medio Oeste americano, un relato suyo fue rechazado "por faltar al sagrado código del realismo mágico" ("Presentación” 10). De esta experiencia nacería la antología que editó con Sergio Gómez. En el 2000 aparecería otra antología editada por Paz Soldán y Fuguet, Se habla español: Voces latinas en USA. En una entrevista publicada en la Barcelona Review, Paz Soldán explica que "La antología [McOndo] [...] era un intento de presentar una muestra de la nueva narrativa latinoamericana: urbana, hiperreal, reacia al realismo mágico, muy a tono con la cultura popular norteamericana y con las nuevas tecnologías que iban apareciendo en el paisaje del continente” (24). Sobre el movimiento McOndo y la hibridez cultural, véase también la antología crítica que Paz Soldán editó con Debra A. Castillo y el valiosísimo estudio de García Canclini.

$\begin{array}{llrrr}\text { Revista Iberoamericana, Vol. LXXVIII, Núms. 238-239, } & \text { Enero-Junio 2012, } & \text { 193-208 } \\ \text { ISSN 2154-4794 (Electrónico) }\end{array}$ 
tradiciones, ya lo sabemos, se pueden tornar agobiantes cuando se las vive como obligaciones" (“Escritor” 24). Los rasgos de esta nueva literatura incluyen, además del ambiente metropolitano y el protagonismo joven, un realismo que no se corta en la representación de los efectos de la globalización: el desempleo, los “McJobs” exportados por las empresas multinacionales, el crimen, la pobreza y el sistema de clases. Demuestra la desaparición de la separación entre la cultura popular y la alta cultura: conviven referencias "pop" al lado de alusiones a obras artísticas consagradas. De igual manera, Fuguet y Gómez propusieron una escritura que borrara la frontera entre Norte y Sur porque "[t]emerle a la cultura bastarda es negar nuestro propio mestizaje" (15); y porque "[e]l mundo se empequeñeció y compartimos una cultura bastarda similar, que nos ha hermanado irremediablemente sin buscarlo. Hemos crecido pegados a los mismos programas de la televisión, admirado las mismas películas y leído todo lo que se merece leer, en una sincronía digna de considerarse mágica” (18). Como consecuencia, en esta literatura se hace patente el efecto hibridizante de la "mass media": aparecen el inglés y el "spanglish" al lado del español. Como tan acertadamente señaló Néstor García Canclini, a la luz de las "new modalities of organization of culture and hybridization of the traditions of classes, ethnic groups, and nations [...] all cultures are border cultures" (206-7). Es obvio que Trujillo Muñoz, aunque optase por el camino de la ciencia ficción, compartía una de las grandes preocupaciones temáticas de los McOndo: el efecto hibridizante de la globalización.

Laberinto acaba, apropiadamente, con un fragmento del diario de Josel en el cual los tripulantes opinan sobre la índole de la nueva realidad posderridación, cada uno según quién y cómo es:

La vida que hoy vivimos, multidimensional, como la llama Irene Dax; cachonda y libertaria, como la denomina Francisco Sing; rigurosa y ética, como la cataloga Lena Brodsky; comunicacional y con todos sus canales abiertos, como la considera Cristobal Monk, es un crisol de razas, un mestizaje continuo. Eso es lo importante. Eso -y no las muchas muertes que le hemos ocasionado a Hans Boder- es nuestro legado a la humanidad, el más vivo y auténtico, el más perdurable. (140)

Y también, se espera, el legado de esta novela.

ISSN 0034-9631 (Impreso) 
OBRAs CITADAS

Battersby, Christine. The Sublime, Terror, and Human Difference. Londres: Routledge, 2007.

Beverley, John y otros, ed. The Postmodernism Debate in Latin America. Durham: Duke UP, 1995.

Bieder, Mary Ellen. “Intertextualizing Genre: Ambiguity as Narrative Strategy in Emilia Pardo Bazán.” Intertextual Pursuits: Literary Meditations on Modern Spanish Narrative. Jeanne P. Brownlow, ed. Lewisberg: Bucknell UP, 1998. 57-75.

Burke, Edmund. A Philosophical Enquiry into the Origin of Our Ideas of the Sublime and the Beautiful. Adam Phillips, ed. Oxford: Oxford UP, 1990.

Childs, Peter. Modernism. 2a ed. Londres: Routledge, 2008.

Cirlot, J. E. A Dictionary of Symbols. Jack Sage, trad. Londres: Routledge and Keagan Paul, 1971.

Derrida, J. Writing and Difference. A. Bass, trad. Londres: Routledge, 1978.

Deutsch, David. The Fabric of Reality: The Science of Parallel Universes-and its Implications. Londres: Allen Lane/Penguin, 1997.

Eliot, T. S. “The Waste Land”. Collected Poems: 1909-1935. 1922. Nueva York: Harcourt, Brace and Company, 1930. 69-90.

Fabriol, Anaïs I. La frontera en la narrativa de Gabriel Trujillo Muñoz. Mexicali: Crunch!Editores, 2005.

Fernández, Miguel Ángel. “Panorama de la ciencia-ficcion mexicana”. Ciencia Ficción Mexicana. 2005. <http://www.ciencia-ficcion.com.mex/?uid2\&cve=11:26>. 4 mar. 2010.

"Los cartógrafos del infierno en México: panorama de la ciencia ficción en México”. Literatura virtual. 2002. <http://www.angelfire.com/va3/literatura/ CIENCIAFICCION.htm>. 4 mar. 2010.

Fuguet, Alberto y Sergio Gómez. "Presentación”. McOndo. Alberto Fuguet y Sergio Gómez, eds. México: Grijalbo Mondadori, 1996. 9-22.

García Canclini, Néstor. Hybrid Cultures: Strategies for Entering and Leaving Modernity. Christopher L. Chiappari y Silvia L. López, trads. Minneapolis: U of Minnesota P, 1995.

“Cultural Reconversion”. On the Edge: The Crisis of Contemporary Latin American Culture. Holly Staver, trad. George Yúdice y otros, eds. Minneapolis: U of Minnesota P, 1992. 29-43.

Heidegger, Martin. Being and Time. Joan Stambaugh, trad. Albany, NY: State U of New York P, 1996.

Hopenhayn, Martín. No Apocalypse, No Integration. Modernism and Postmodernism in Latin America. Durham: Duke UP, 2001.

Hutcheon, Linda. The Politics of Postmodernism. Londres: Routledge, 1989.

Revista Iberoamericana, Vol. LXXVIII, Núms. 238-239, Enero-Junio 2012, 193-208
ISSN 2154-4794 (Electrónico) 
Kant, Immanuel. Immanuel Kant's Critique of Pure Reason. N. Kemp-Smith, ed. Londres: Macmillan, 1965.

Kirwan, James. Sublimity: The Non-Rational and the Irrational in the History of Aesthetics. Londres: Routledge, 2005.

Larsen, Neil. "Posmodernismo e imperialismo: teoría y política en Latinoamérica”. Nuevo Texto Crítico 6 (1990): 77-94.

Lockhart, Darrell B., Ed. Latin American Science Fiction Writers: An A-to-Z Guide. Westport, CT: Greenwood Press, 2004.

Lyotard, Jean-François. The Postmodern Condition: A Report on Knowledge. 1979. Geoff Bennington y Brian Massumi, trad. Minneapolis: U of Minnesota P, 1984. "The Sublime and the Avant-Garde". The Lyotard Reader. Andrew Benjamin, ed. Oxford: Basil Blackwell, 1989. 196-211.

Martré, Gonzalo. La ciencia ficción en México (hasta el 2002). México, DF: Instituto Politécnico Nacional, 2004.

Moore, Burness E. y Bernard D. Fine. Psychoanalytical Terms and Concepts. New Haven: Yale UP, 1990.

Munch Edvard. Skrik [El grito]. 1893. Oleo sobre lienzo. Galería Nacional de Noruega.

Paz Soldán. "El escritor, McOndo, y la tradición”. Barcelona Review 42 (junio 2004): 24. y Debra A. Castillo eds. Latin American Literature and Mass Media. Nueva York: Garland, 2001. y Alberto Fuguet. "Prólogo”. Se habla español: Voces latinas en USA. Edmundo Paz Soldán y Alberto Fuguet, eds. Miami: Alfaguara, 2000. 13-22.

Rainey, Lawrence S. Revisiting "The Waste Land”. New Haven: Yale UP, 2005.

Rees, Martin. Before the Beginning. Reading, MA: Helix Books, 1997.

Shaw, Philip. The Sublime. Londres: Routledge, 2006.

Suvin, Darko. Metamorphoses of Science Fiction: On the Poetics and History of a Literary Genre. New Haven: Yale UP, 1979.

Triumph des Willens. Dir. Leni Riefenstahl. Universum Film AG, 1935.

Trujillo Muñoz, Gabriel. Espantapájaros. México: Lectorum,1999.

Highclowd. Memorias de arena y agua, de roca y viento. México: UNAM, 2006. Laberinto (As Time Goes By). Mexicali: Instituto de Cultura de Baja California, 1995. Mexicali City Blues. Montreal: Allusifs, 2009. Mezquite Road. Madrid: Planeta, 1995. Tijuana City Blues. Montreal: Allusifs, 2009. Transfiguraciones. Un misterio venerable. México: Jus, 2008.

Wolin, Richard. "Preface to the MITPress Edition: Note on a Missing Text". The Heidegger Controversy: A Critical Reader. R. Wolin, ed. Cambridge: MIT P, 1993. ix-xx.

Yúdice, George. “¿Puede hablarse de posmodernidad en América Latina?”. Revista de Crítica Literaria Latinoamericana 29 (1989): 105-28.

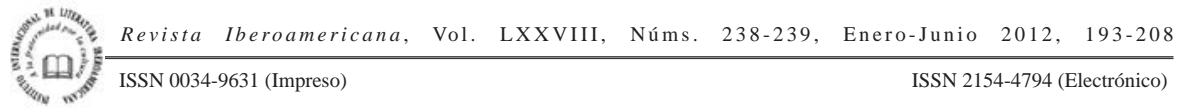

